\title{
Sexually dimorphic effects of a prenatal immune challenge on social play and vasopressin expression in juvenile rats
}

Patrick V Taylor ${ }^{1}$, Alexa H Veenema ${ }^{2}$, Matthew J Paul ${ }^{1}$, Remco Bredewold², Stephanie ssaacs $^{1}$ and Geert J de Vries ${ }^{1 *}$

\begin{abstract}
Background: Infectious diseases and inflammation during pregnancy increase the offspring's risk for behavioral disorders. However, how immune stress affects neural circuitry during development is not well known. We tested whether a prenatal immune challenge interferes with the development of social play and with neural circuits implicated in social behavior.
\end{abstract}

Methods: Pregnant rats were given intraperitoneal injections of the bacterial endotoxin lipopolysaccharide (LPS $-100 \mu \mathrm{g} / \mathrm{kg}$ ) or saline on the 15th day of pregnancy. Offspring were tested for social play behaviors between postnatal days 26-40. Brains were harvested on postnatal day 45 and processed for arginine vasopressin (AVP) mRNA in situ hybridization.

Results: In males, LPS treatment reduced the frequency of juvenile play behavior and reduced AVP mRNA expression in the medial amygdala and bed nucleus of the stria terminalis. These effects were not found in females. LPS treatment did not change AVP mRNA expression in the suprachiasmatic nucleus, paraventricular nucleus, or supraoptic nucleus of either sex, nor did it affect the sex difference in the size of the sexually dimorphic nucleus of the preoptic area.

Conclusions: Given AVP's central role in regulating social behavior, the sexually dimorphic effects of prenatal LPS treatment on male AVP mRNA expression may contribute to the sexually dimorphic effect of LPS on male social play and may, therefore, increase understanding of factors that contribute to sex differences in social psychopathology.

Keywords: Lipopolysaccharides, Bed nucleus of the stria terminalis, Medial amygdaloid nucleus, Prenatal, Play behavior, Sex differences, SDN-POA, Development

\section{Background}

Children of mothers who were afflicted by an infectious disease during pregnancy have a higher risk for schizophrenia, autism spectrum disorders, mental retardation, and other mental disorders [1,2]. Animal models used to study the effects of infectious disease during development often use lipopolysaccharide (LPS), a noninfectious bacterial antigen derived from the cell wall of gram negative bacteria to activate the immune system [3]. For example, mice whose mothers were treated with

\footnotetext{
*Correspondence: devries@cns.umass.edu

${ }^{1}$ Center for Neuroendocrine Studies and Department of Psychology,

University of Massachusetts, Amherst, MA 01003, USA

Full list of author information is available at the end of the article
}

LPS during pregnancy show less aggression and more social grooming behavior in adulthood [4]. Remarkably, although many disorders of social behavior emerge during childhood, very few studies have addressed the effects of prenatal immune activation on social behavior during development.

We hypothesized that prenatal immune activation alters juvenile social play behavior just as it alters adult behavior, and that it does so by changing neural circuitry involved in social behavior. We focused on social play, which in rats is the primary social behavior performed during pre-pubertal life [5], and on the AVP innervation of the brain, as this system (or its non-mammalian homologue vasotocin innervation) has been implicated

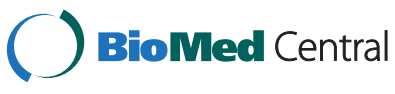


in a wide variety of social behaviors across a broad range of species [6,7]. Moreover, blocking AVP receptors centrally reduces social play in 35-day-old male rats while increasing it in females [8], and postnatal stressors that affect social play in rats modify AVP expression in the paraventricular nucleus (PVN) and supraoptic nucleus (SON) [9]. Given that developmental perturbations, including LPS treatment, often affect males and females differently $[10,11]$, and that AVP innervation is highly sexually dimorphic in rats [12], we compare the effects of LPS on both sexes. We find that prenatal LPS exposure reduces juvenile play behavior and AVP mRNA expression in the medial amygdaloid nucleus (MeA) as well as the bed nucleus of the stria terminalis (BST) in male but not in female rats. Since the MeA is known to be important for normal levels of social play behavior in males but not in females [13], these results suggest a way in which prenatal immune activation may differentially affect the development of social behavior in males and females.

\section{Methods \\ Animals}

Adult Wistar rats were obtained from Charles River, Wilmington, MA, and paired for mating. The day a sperm plug was found was defined as embryonic day 0 (E0). Males were removed that day, and females were housed individually in standard rat cages under a 14:10 light:dark cycle with lights off at $10 \mathrm{am}$. Temperature was maintained at $22{ }^{\circ} \mathrm{C}$. Food and water were provided ad libitum. Animals were not maintained under specified pathogen free (SPF) conditions. All procedures were conducted in accordance with the NIH Guide for the Care and Use of Laboratory Animals and approved by the Institutional Animal Care and Use Committee.

\section{Experimental design}

On E15, dams were injected intraperitoneally with $100 \mu \mathrm{g} / \mathrm{kg}$ LPS (E. coli O26:B6; Sigma-Aldrich, St. Louis, $\mathrm{MO}$ ) or sterile saline. LPS was chosen as it is one of the most commonly used immune stimulants, for which many of the cellular inflammatory cascades have been worked out; the dose of $100 \mu \mathrm{g} / \mathrm{kg}$ of LPS is commonly used in studies of prenatal effects of immune stimulation [14]. Following injection, the dams were monitored twice daily for two days to check for overt signs of sickness as defined by the National Research Council's 1996 Guide for the Care and Use of Laboratory Animals. Within one day after birth, litters were culled to produce litter sizes between four and six pups, and the number of males and females was kept equal across treatment. Litters were weaned at 22 days of age (day of birth being day 0 ) and housed in sex-mixed groups at 25 days of age, resulting in seven saline litters and five LPS litters.
Behavior of offspring was digitally video-recorded on five different days between 26 to 40 days of age. Animals were weighed at 35 and 45 days of age. At 45 days of age, all offspring were killed, their brains removed and snap-frozen in 2-methyl-butane on dry ice. Brains were stored at $-80{ }^{\circ} \mathrm{C}$. For ease of description, animals from LPS treated-dams will be called 'LPS Males' and 'LPS Females', the control animals will be called 'Saline Males' and 'Saline Females.'

\section{Play behavior}

Play behavior was assessed at the beginning of the dark phase. Rats were habituated to the testing condition by moving the home cage into the testing room for three hours on two consecutive days prior to the tests. All animals were tested under two different conditions on the following days: (1) in treatment-matched pairs (LPS pairs and saline pairs at 26, 37, and 42 days of age), and (2) treatment-mixed pairs (LPS/saline pairs at 30 and 40 days of age). Rats were housed individually in a new cage for $1 \mathrm{~h}$ before being paired with a sex- and age-matched rat. Treatment-matched pairs came from the same home cage. After recording behavior for $10 \mathrm{~min}$, rats were returned to their home cage. At 35 days of age, 22 rats were sacrificed, and their brains set aside for future analysis. A researcher blind to the treatment conditions used JWatcher software (www.jwatcher.ucla.edu) to score the frequency of Boxing \& Wrestling, Pinning, and Pouncing, as defined in [15]. Total Play was calculated as the total of these three frequencies.

\section{In situ hybridization}

Each brain was cut transversally at $12 \mu \mathrm{m}$ into three series, thaw-mounted onto Colorfrost/plus slides (Thermo Fisher Scientific, Pittsburgh, PA), and stored at $-80{ }^{\circ} \mathrm{C}$. One series of sections was postfixed in $4 \%$ paraformaldehyde for $5 \mathrm{~min}$ and rinsed in $0.1 \mathrm{M}$ phosphate-buffered saline ( $\mathrm{pH}$ 7.4) for $2 \mathrm{~min}$, both solutions at $4{ }^{\circ} \mathrm{C}$. In situ hybridization was performed as published previously $[16,17]$ using a mixture of two oligodeoxyribose antisense probes. Probe 1 and 2 are complementary to the regions that code for amino acids 127-141 and 143-159 of the AVP prohormone, which are in the glycopeptide region near the $\mathrm{COOH}$-terminal. The probes were labeled at the 3' end with 35 S-dATP (PerkinElmer, Waltham, MA) using terminal deoxynucleotidyl transferase (Life Technologies Inc., Gaithersburg, MD). To locate the hybridization signal, slides were dipped in Kodak NTB-3 emulsion under safelight and stored desiccated in light tight boxes at $4{ }^{\circ} \mathrm{C}$. After four weeks, slides were developed with Kodak D19 developer (1:1 with purified water) and fixed with Kodak Rapid Fix. Slides were rinsed in purified water, lightly counterstained with $2 \%$ methyl green, dehydrated with 
$50 \%$ ethanol, and coverslipped with Cytoseal 60 (Richard-Allen Scientific, Kalamazoo, MI).

\section{AVP mRNA analysis}

For analysis of sections processed for AVP mRNA in situ hybridization, cells with a density of silver grains above background were counted in every third section by two observers blind to the treatment. Labeled cells in the bed nucleus of the stria terminalis (BST) and medial amygdaloid nucleus (MeA) were identified under darkfield illumination using a $20 \mathrm{X}$ objective and counted only if brightfield microscopy confirmed a methyl greenstained nucleus underneath the silver grains. As crowding of labeled cells prevented counting individual cells in the suprachiasmatic nucleus (SCN), supraoptic nucleus (SON), and paraventricular nucleus (PVN), AVP mRNA expression in these nuclei was digitally photographed throughout their rostro-caudal extent using a $4 \mathrm{X}$ objective under bright-field illumination. For each nucleus, we determined the total area above background and the integrated optical density (calculated as total area above background times average gray value $(0-255)$ of thresholded pixels) using Image J software (NIH, Bethesda, $\mathrm{MD})$.

\section{Volume of the sexually dimorphic nucleus of the preoptic} area

As LPS treatment blunted the sex difference in AVP mRNA expression in the BST and MeA, we tested whether LPS had general effects on sexual differentiation by measuring the volume of the sexually dimorphic nucleus of the preoptic area (SDN-POA) [18]. Sections at the level of the SDN-POA from the second series of slides were thawed and allowed to dry at room temperature for $10 \mathrm{~min}$, delipidated with a graded ethanol series and thionin-stained. Sections were coverslipped using permount (SP15-500, Fisher Scientific). Each section containing the SDN-POA was digitally photographed throughout the rostro-caudal extent of the nucleus using a $4 \mathrm{X}$ objective under bright-field illumination. An experimenter blind to the treatment traced and measured the area throughout the SDN-POA using Image J software (NIH, Bethesda, MD). Volume was calculated as the sum of area $\times 3 \times 12 \mu \mathrm{m}$.

\section{Statistical analysis}

To determine whether play behaviors differed significantly across age, paired t-tests were conducted on each behavioral measure (Total Play, Boxing \& Wrestling, Pinning, and Pouncing) for all pairwise age combinations in matched pairs (P26 vs. P37, P37 vs. P42, and P26 vs. P42) and Mixed Pairs (P30 vs. P40). Out of these 24 comparisons, only one differed significantly between age groups (Pouncing at P26 vs. P37, p < 0.05). Because there was no systematic effect of age, all further behavioral analyses were based on individuals' mean score (mean Total Play, mean Boxing \& Wrestling, etc.). To avoid litter effects, behavioral scores and neural measures for males and females were averaged by litter and then analyzed using a two-way ANOVA (Sex X Treatment), see ref [19]. Planned comparisons (Fisher's PLSD) were performed to evaluate 1) sex differences (Saline Males versus Saline Females), 2) LPS effects in males (LPS Males versus Saline Males), and 3) LPS effects in females (LPS Females versus Saline Females). Analyses were conducted using Statview 5.0.1 (SAS Institute Inc., Cary, NC).

\section{Results}

\section{General effects of LPS exposure}

Dams injected on embryonic day 15 showed increased red lachrymal secretions for one day following LPS injection, but no other overt signs of sickness were observed, and pregnancies were not aborted. LPS did not affect litter size or sex ratio, and pups showed no gross abnormalities.

\section{Development of social play behavior}

In total, behavior was tested in twentyeight male and thirtyone female pups derived from seven saline-treated and five LPS-treated litters. As the data were averaged by litter, $\mathrm{n}=7$ per group was used for saline-treated individuals and $n=5$ per group for LPS-treated individuals in the statistical analysis. In treatment-matched pairs, maternal LPS injection significantly reduced Total Play in males but not in females, which was reflected in a significant sex $\mathrm{X}$ treatment interaction (Figure 1; F $(1,20)=10.19, \mathrm{p}<0.005)$. Consistent with previous findings [20,21], Saline Males played significantly more than Saline Females (Figure 1; planned comparison, $\mathrm{p}<0.05$ ). To determine whether the LPS effect was evident in specific play behaviors, we analyzed Boxing \& Wrestling, Pouncing, and Pinning separately. Both Boxing \& Wrestling as well as Pinning exhibited the same significant sex $\mathrm{X}$ treatment interaction seen in Total Play (Figure 1; F $(1,20)=14.45, \mathrm{p}<0.002$ for Boxing and Wrestling and $\mathrm{F}$ $(1,20)=5.37, \mathrm{p}<0.04$, for Pinning). No main effects or interactions were found for Pouncing (Figure 1). As males and females have different developmental trajectories, with females reaching puberty earlier, differences in maturation could contribute to sex differences in LPS effects. However, females showed no LPS effects at any of the ages that behavior was measured.

As social play is dyadic, potential effects of LPS in an animal may also depend on treatment of its partner. Therefore, we tested LPS effects in mixed-treatment pairs as well (treatment-mixed pairs). Also in this case, group means exhibited a similar trend. For example, LPS 


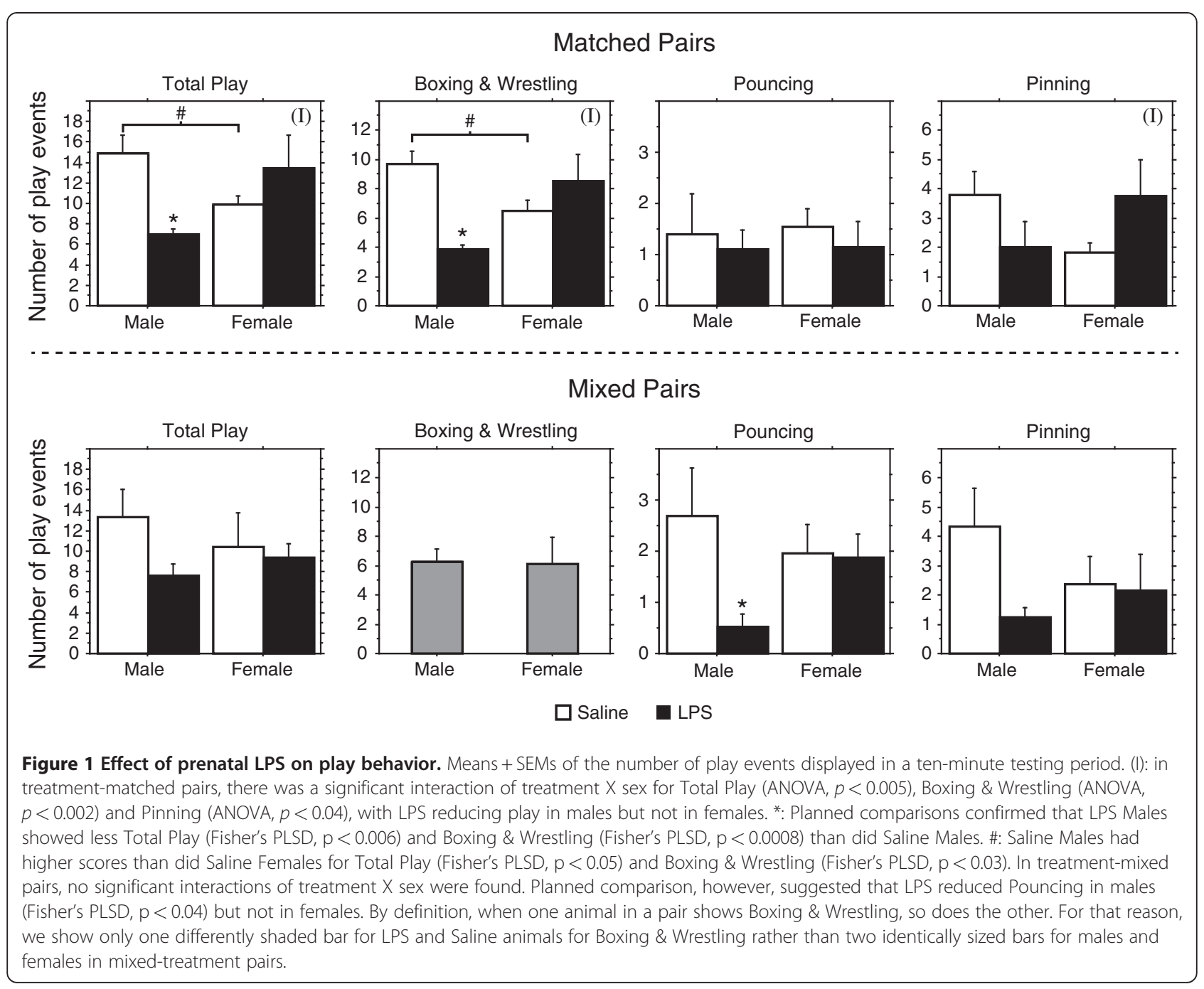

marginally reduced Pouncing and Pinning in males (planned comparisons, $\mathrm{p}<0.04$ and $\mathrm{p}=0.06$ for Pouncing and Pinning, respectively) but not in females (Figure 1). Treatment differences in Total Play, however, were blunted and not significant (Figure 1). Given that Boxing \& Wrestling is by definition displayed by both animals of the pair at the same time (indicated by the gray columns in Figure 1), and given also that it comprises a large proportion of Total Play, it may have masked an LPS effect on Total Play in mixed pairs. Matched and mixed pairs also differed in their familiarity with the play partner, with matched animals being paired with a cage mate and mixed animals with an unfamiliar animal. It is possible that differences between LPS and Saline Males would have been more, or perhaps less pronounced if treatment-matched animals would have been tested with unfamiliar cage mates.

Sex differences in LPS effects on play behavior were clearest in matched pairs. In treatment-mixed pairs, fewer sex differences were found, perhaps because the
LPS Males might have been less inclined to play, thereby bringing down the overall score of their Saline Male partners. In support, in mixed pairs, Pinning was marginally higher in Saline than in LPS Males (Figure 1 planned comparison, $\mathrm{p}=0.06$ ).

\section{LPS effect on AVP mRNA expression}

In total, thirty brains were processed for AVP mRNA expression from male and female pups derived from three LPS-treated and three saline-treated litters. Due to poor histology some material could not be analyzed: 1 brain was excluded for the MeA, 4 for the BNST and SCN, 5 for the SON, and 6 for the PVN. As the data were averaged by litter, $\mathrm{n}=3$ per group was used for statistical analysis. Significant effects of LPS treatment on AVP mRNA expression were only found in the MeA and BST (Figure 2). Confirming the literature [22], juvenile males showed more AVP mRNA-expressing cells in the MeA and BST than females, (Figure 3; F $(1,8)=146.98, p$ $<0.0001 ; \mathrm{F}(1,8)=236.2, \mathrm{p}<0.0001$ for $\mathrm{MeA}$ and BST, 

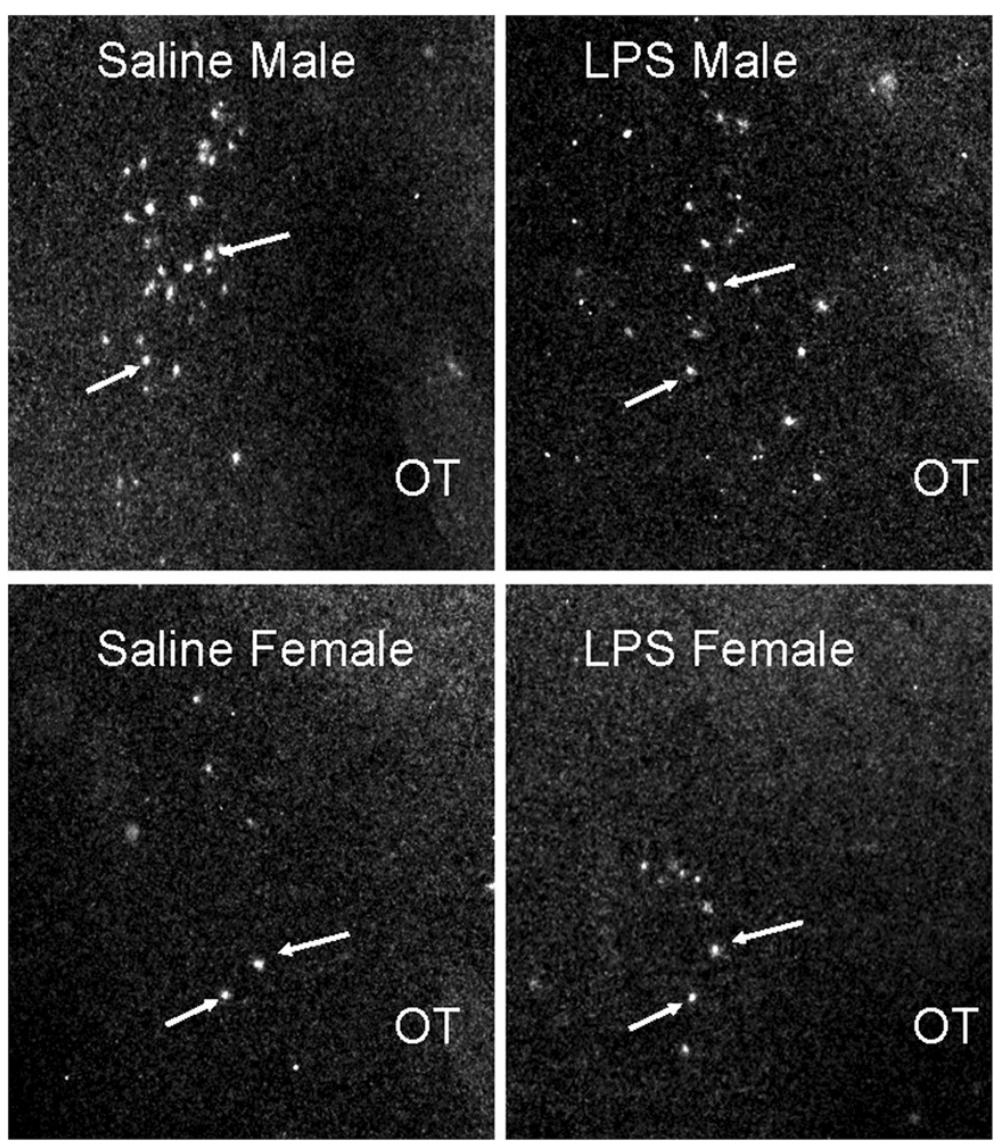

Figure 2 AVP mRNA expression in the medial amygdaloid nucleus (MeA). Photomicrographs show sections processed with in situ hybridization for AVP mRNA. Arrows indicate individual cells labeled for AVP mRNA; ot: optic tract.

respectively). LPS treatment reduced AVP expression in males but not in females, thereby causing significant treatment $\mathrm{X}$ sex interactions in the MeA and BST (Figure 3; $\mathrm{F}(1,8)=6.11, \mathrm{p}<0.04 ; \mathrm{F}(1,8)=7.45, \mathrm{p}<0.03$ for MeA and BST, respectively). These sex-specific effects of LPS were restricted to the BST and MeA, as there were no LPS effects on AVP mRNA expression in the SON, PVN, or SCN (Figure 4). In accord with what has been reported for the size of the SON and its AVP neurons in 60-day old rats [23], we found that volume of the area expressing AVP mRNA and integrated density of AVP mRNA expression in the SON are larger in males than in females (Figure 4; $F(1,8)=12.57, \mathrm{p}<0.008$ and $F(1,8)=12.86, p<0.008$ for volume and integrated density, respectively).

\section{Prenatal immune activation does not impact sexual differentiation of the SDN-POA}

In total, thirtytwo brains were thionin-stained from male and female pups derived from four saline and three LPStreated litters. As the data were averaged by litter, $n=4$. (saline) and $n=3$ (LPS) per group was used for statistical analysis. As in adult animals [18] the SDN-POA was about three times larger in males than in females (Figure 5; $\mathrm{F}(1,10)=78.92, \mathrm{p}<0.0001$ ). LPS treatment had no effect on this difference.

\section{Discussion}

We found that treating rats with LPS on day 15 of pregnancy reduced social play of male but not of female offspring. Only one other study reports that LPS exposure on day 9.5 of pregnancy reduces play in male offspring; no females were studied, and no effects were found on gross morphology of the brain [24]. We found that, in addition to social play, LPS reduced AVP expression in the BST and MeA, again in male but not in female offspring. Therefore, our findings suggest that the often-made observation that males are more vulnerable to prenatal stress than females $[25,26]$ can be extended to the neural substrate underlying social behavior in juvenile animals.

Social play as well as AVP expression in the BST and MeA are more prominent in male than in female juveniles $[20,22]$. As LPS treatment reduced social play and 


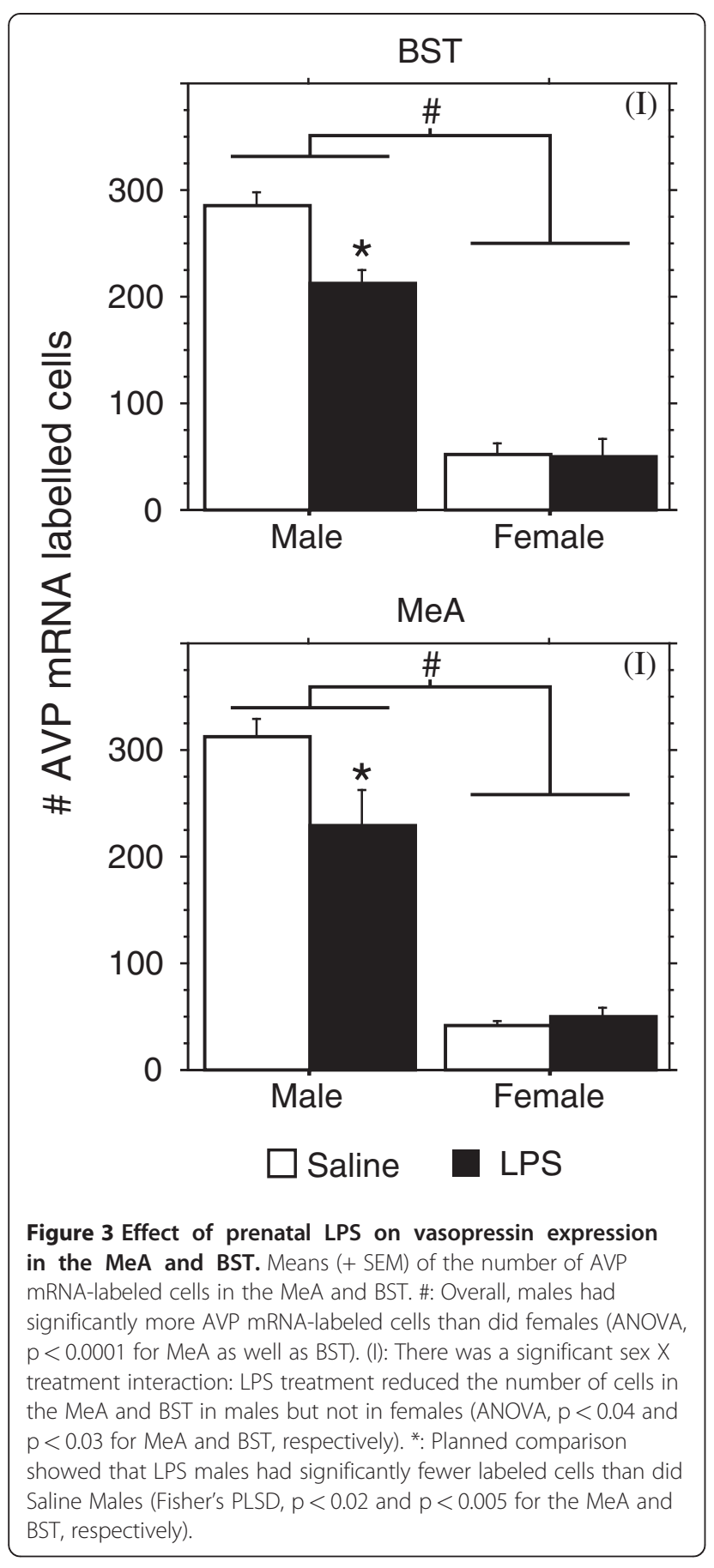

AVP expression in males only, LPS treatment may have interfered with general mechanisms of sexual differentiation. For example, malnutrition or environmental stress in the last week of pregnancy reduces differentiation of sexual behavior and SDN-POA volume [27]. A stresslinked reduction in fetal activity of testosterone may contribute to this effect $[28,29]$. As sexual differentiation of play behavior and AVP expression depends on higher levels of testosterone in males [30-33], LPS may have inhibited masculinizing effects of testosterone. Our data, however, argue against a general effect of LPS on sexual differentiation, as the volume of the SDN-POA was unaffected by LPS treatment.

There are several other possible explanations as to why LPS treatment affected AVP expression in males but not in females in the present study. Humoral factors generated as a result of LPS treatment may have differential access to male and female fetuses. For example, stress early in pregnancy significantly changes the expression of genes implicated in the hypoxic response, cell differentiation, and metabolism in male but not in female placentas [34]. Immune challenges may have similar dimorphic effects on the placenta, thereby possibly differentially affecting the exchange of nutrients, metabolic waste products, and signaling molecules across the placental barrier.

LPS treatment may also have made AVP cells less sensitive to the masculinizing effects of gonadal steroids postnatally. Higher levels of testosterone found in males increase the probability that developing neurons in the BST and MeA commit to a vasopressinergic phenotype $[35,36]$. Given that LPS effects were only significant in males, LPS may have interfered with this differentiating step. Interestingly, sexual differentiation of specific brain areas and behaviors uses components of signal transduction pathways that are common to inflammatory processes [37-39]. As AVP cells in the BST are affected by inflammatory processes in adult animals [40], there may be cross-talk between sexual differentiation and immune signaling pathways during their development as well.

Several lines of evidence suggest that the LPS-induced reduction in play behavior and in AVP mRNA expression in the MeA are causally related. AVP has been implicated in the control of social behavior [6,41]. Moreover, injecting an AVP receptor antagonist intracerebroventricularly reduces play behavior in males [8]. Furthermore, systemic testosterone can masculinize play behavior as well as AVP expression in the MeA and BST by acting on androgen rather than estrogen receptors $[30,33]$, and intracranial testosterone implants placed specifically into the amygdala masculinize social play [31]. It is not yet known whether AVP treatment can reverse the reduction in play behavior in LPS Males.

The LPS-induced reduction in AVP mRNA was specific to the BST and MeA, as levels did not change it in the SON, PVN, or SCN. Differences in birth date of AVP neurons may contribute to differences in LPS effects on various AVP-expressing brain regions in this study. AVP neurons in the BST and MeA are born on embryonic days 11 and $12[42,43]$ and therefore all of these cells could be affected by LPS treatment on embryonic day 15. In contrast, SCN cells are born on embryonic days 14-17 [44], which is, by and large, at or after the LPS treatment given in this paper. Differences in 

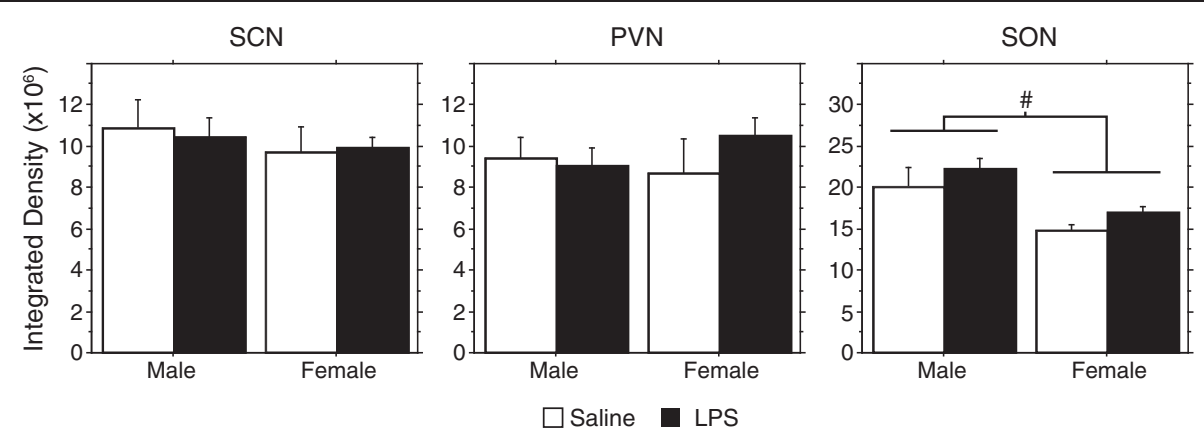

Figure 4 Lack of effect of prenatal LPS on vasopressin expression in the SCN, PVN, and SON. Means (+ SEM) of the integrated density of AVP mRNA labeling in the SCN, PVN, and SON. Although there was no effect of LPS treatment, overall, males showed higher integrated density in the SON than did females (ANOVA, $p<0.008$ ).

developmental trajectory may also shelter the PVN and $\mathrm{SON}$, as neurons in these nuclei are born on embryonic days $12-18$. Thus only a fraction of the cells are born by the time LPS was administered [44].

BST and MeA cells appear to be responsive to immune challenges in adulthood as well. In adult rats, LPS treatment acutely increases AVP release in the ventral septal area [45], a projection area of AVP neurons of the BST and MeA [46], and treatment with the pro-inflammatory cytokine interleukin-1beta, which is released upon exposure to LPS, increases the firing rate of BST and MeA neurons [47]. These effects have been linked to AVP's role in fever abatement [40]. We propose that LPS treatment early in life may activate these same neurons, thereby permanently changing their impact on physiology and behavior. A relevant example of such programming is found in the administration of LPS early postnatally, which permanently alters the fever response, interestingly, more so in males than in females [48].

As of yet it is unclear what molecular mechanisms underlie LPS-induced changes in AVP expression and

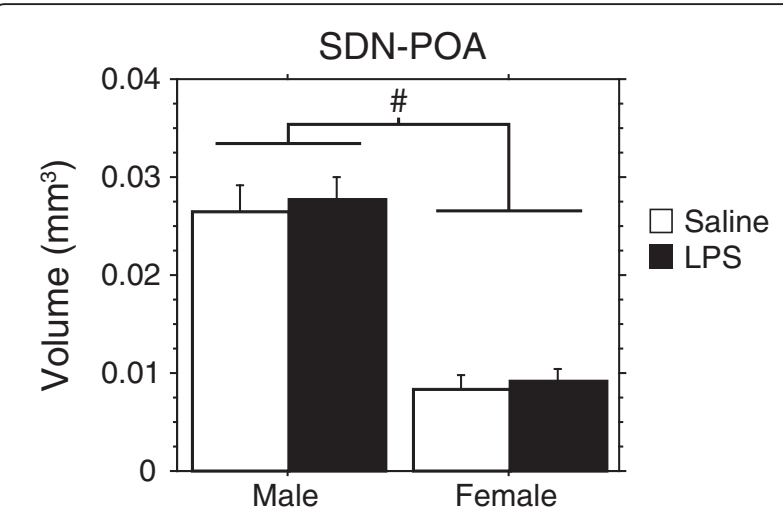

Figure 5 Effect of prenatal LPS on the volume of the SDN-POA. Means (+ SEM) of the volume of the SDN-POA. \#: The volume of the SDN-POA is significantly larger in males than in females (ANOVA: $p<0.0001$ ). LPS did not affect the volume of the SDN-POA. play behavior. Most likely, early immune activation altered the fate of a number of cells, perhaps by changing epigenetic regulation of AVP gene expression. Such long-term changes have been shown for the PVN, where early life stress increases AVP expression while reducing methylation of $\mathrm{CPG}$ sites of a chromosomal region that controls AVP expression [49]. Related epigenetic changes might underlie the effects of prenatal immune activation on social behaviors reported here.

In addition to LPS treatment directly affecting fetal development, it may have altered maternal behavior, and thereby development. Several studies suggest that this is not likely. For example, dams injected with the same dose of LPS used in this study, but on embryonic day 15 as well as day 16, did not show changes in parental care [50]. In addition, stress during fetal development changes social behavior and expression of oxytocin mRNA in the PVN of adult male rats, irrespective of whether they were raised by stressed or unstressed dams [51]. However, given the role of maternal care in male sexual differentiation [52], the possibility remains that changes in maternal behavior may have mediated or masked potential effects of prenatal LPS.

\section{Conclusions}

This study demonstrated that LPS treatment on day 15 of pregnancy affects play behavior in male but not in female offspring. Likewise, LPS treatment reduces AVP expression in male but not in female offspring, specifically in AVP-expressing nuclei that have been implicated in social behavior. Conditions that activate the immune response during pregnancy increase the frequency of diagnoses for autism, schizophrenia, and depression [1,2]. Interestingly, all these disorders are sexually dimorphic with respect to onset, course, and incidence. For example, schizophrenia is more common in men [53], and autism is more common in boys [54]. Sex differences in vulnerability to stress may be due to differences in neural systems that modulate social behavior, such as 
the AVP system. Indeed, converging evidence suggests that AVP may be involved in social disorders such as autism $[55,56]$ as well as in normal aspects of human social behavior [57,58]. The evidence for involvement of AVP in social behaviors such as social recognition, parental, and aggressive behaviors is even stronger in laboratory animals $[7,41,59,60]$. Interestingly, AVP influences social behavior differently in male and female rodents [61]. The same may be true in humans as well [57]. If so, developmental perturbation of AVP innervation is prone to affect one sex more than the other. In that regard, the influence of LPS on the development of social play may be a good model for understanding factors that contribute to sex differences in social psychopathology.

\section{Abbreviations}

AVP: Arginine vasopressin; LPS: Lipopolysaccharide; MeA: Medial amygdala; SON: Supraoptic nucleus; PVN: Paraventricular nucleus; BST: Bed nucleus of the stria terminalis; SCN: Suprachiasmatic nucleus; SDN-POA: Sexually dimorphic nucleus of the preoptic area; mRNA: Messenger RNA.

\section{Competing interests}

All authors declare that there are no conflicts of interests

\section{Acknowledgements}

We thank Thalia Taylor and Drs. Elaine Murray and Nancy Forger for comments on the paper and experimental methods. The research was funded by KO2 MH01497 and RO1 MH47538 and T32 MH020051.

\section{Author details}

${ }^{1}$ Center for Neuroendocrine Studies and Department of Psychology, University of Massachusetts, Amherst, MA 01003, USA. ²Department of Psychology, Boston College, Chestnut Hill, MA 02467, USA.

\section{Authors' contributions}

PVT and GJD conceived of and designed the study. PVT, AHV, RB, and SI treated the animals and video-taped their behavior. PVT, AHV, MJP, and SI developed and participated in the scoring of video-recorded behaviors. PVT, $\mathrm{RB}, \mathrm{SI}$, and GJD processed brains histologically and performed microscopic analysis of brain tissue. PVT, MJP, and GJD performed the statistical analysis. PVT, GJD, and MJP drafted the manuscript, and all authors read, made suggestions for changes, and approved the manuscript.

Received: 31 January 2012 Accepted: 14 June 2012

Published: 14 June 2012

\section{References}

1. Brown AS, Derkits EJ: Prenatal infection and schizophrenia: a review of epidemiologic and translational studies. Am J Psychiatry 2010, 167:261-280.

2. Patterson PH: Maternal infection and immune involvement in autism. Trends Mol Med 2011, 17:389-394

3. Boksa P: Effects of prenatal infection on brain development and behavior: a review of findings from animal models. Brain Behav Immun 2010, 24:881-897.

4. Hava G, Vered L, Yael M, Mordechai H, Mahoud H: Alterations in behavior in adult offspring mice following maternal inflammation during pregnancy. Dev Psychobiol 2006, 48:162-168.

5. Pellis SM, Pellis VC: Play fighting of rats in comparative perspective: a schema for neurobehavioral analyses. Neurosci Biobehav Rev 1998, 23:87-101.

6. Goodson JL: Nonapeptides and the evolutionary patterning of sociality. Prog Brain Res 2008, 170:3-15.

7. Caldwell HK, Lee H-J, Macbeth AH, Young WS 3rd: Vasopressin: behavioral roles of an "original" neuropeptide. Prog Neurobiol 2008, 84:1-24.
8. Veenema AH, Bredewold R, de Vries GJ: The role of vasopressin and oxytocin in the emergence of social behaviors. Soc Neurosci Abstract 2009, 466:9.

9. Veenema AH, Neumann ID: Maternal separation enhances offensive play-fighting, basal corticosterone and hypothalamic vasopressin mRNA expression in juvenile male rats. Psychoneuroendocrinology 2009, 34:463-467.

10. Goel N, Bale TL: Examining the intersection of sex and stress in modelling neuropsychiatric disorders. J Neuroendocrinol 2009, 21:415-420.

11. Kentner AC, McLeod SA, Field EF, Pittman QJ: Sex-dependent effects of neonatal inflammation on adult inflammatory markers and behavior. Endocrinology 2010, 151:2689-2699.

12. De Vries GJ, Panzica GC: Sexual differentiation of central vasopressin and vasotocin systems in vertebrates: Different mechanisms, similar endpoints. Neuroscience 2006, 138:947-955.

13. Meaney MJ, Dodge AM, Beatty WW: Sex-dependent effects of amygdaloid lesions on the social play of prepubertal rats. Physiol Behav 1981, 26:467-472.

14. Meyer U, Yee BK, Feldon J: The neurodevelopmental impact of prenatal infections at different times of pregnancy: the earlier the worse? Neuroscientist 2007, 13:241-256.

15. Homberg JR, Schiepers OJG, Schoffelmeer ANM, Cuppen E, Vanderschuren $\mathrm{L}$ : Acute and constitutive increases in central serotonin levels reduce social play behaviour in peri-adolescent rats. Psychopharmacology (Berl) 2007, 195:175-182.

16. De Vries GJ, Wang Z, Bullock NA, Numan S: Sex differences in the effects of testosterone and its metabolites on vasopressin messenger RNA levels in the bed nucleus of the stria terminalis of rats. J Neurosci 1994, 14:1789-1794

17. Rood BD, Murray EK, Laroche J, Yang MK, Blaustein JD, De Vries GJ: Absence of progestin receptors alters distribution of vasopressin fibers but not sexual differentiation of vasopressin system in mice. Neuroscience 2008, 154:911-921.

18. Gorski RA, Gordon JH, Shryne JE, Southam AM: Evidence for a morphological sex difference within the medial preoptic area of the rat brain. Brain Res 1978, 148:333-346.

19. Zorrilla EP: Multiparous species present problems (and possibilities) to developmentalists. Dev Psychobiol 1997, 30:141-150.

20. Olioff M, Stewart J: Sex differences in the play behavior of prepubescent rats. Physiol Behav 1978, 20:113-115.

21. Meaney MJ: The sexual differentiation of social play. Psychiatr Dev 1989, 7:247-261.

22. Szot P, Dorsa DM: Differential timing and sexual dimorphism in the expression of the vasopressin gene in the developing rat brain. Brain Res Dev Brain Res 1993, 73:177-183.

23. Madeira MD, Sousa N, Cadete-Leite A, Lieberman AR, Paula-Barbosa MM: The supraoptic nucleus of the adult rat hypothalamus displays marked sexual dimorphism which is dependent on body weight. Neuroscience 1993, 52:497-513.

24. Kirsten TB, Taricano M, Maiorka PC, Palermo-Neto J, Bernardi MM: Prenatal lipopolysaccharide reduces social behavior in male offspring. Neuroimmunomodulation 2010, 17:240-251.

25. Charil A, Laplante DP, Vaillancourt C, King S: Prenatal stress and brain development. Brain Res Rev 2010, 65:56-79.

26. Bale TL: Sex differences in prenatal epigenetic programming of stress pathways. Stress 2011, 14:348-356.

27. Anderson DK, Rhees RW, Fleming DE: Effects of prenatal stress on differentiation of the sexually dimorphic nucleus of the preoptic area (SDN-POA) of the rat brain. Brain Res 1985, 332:113-118.

28. Weisz J, Brown BL, Ward IL: Maternal stress decreases steroid aromatase activity in brains of male and female rat fetuses. Neuroendocrinology 1982, 35:374-379

29. Ward IL, Weisz J: Differential effects of maternal stress on circulating levels of corticosterone, progesterone, and testosterone in male and female rat fetuses and their mothers. Endocrinology 1984, 114:1635-1644.

30. Meaney MJ, Stewart J, Poulin P, McEwen BS: Sexual differentiation of social play in rat pups is mediated by the neonatal androgen-receptor system. Neuroendocrinology 1983, 37:85-90.

31. Meaney MJ, McEwen BS: Testosterone implants into the amygdala during the neonatal period masculinize the social play of juvenile female rats. Brain Res 1986, 398:324-328. 
32. Wang Z, Bullock NA, De Vries GJ: Sexual differentiation of vasopressin projections of the bed nucleus of the stria terminals and medial amygdaloid nucleus in rats. Endocrinology 1993, 132:2299-2306.

33. Han TM, De Vries GJ: Organizational effects of testosterone, estradiol, and dihydrotestosterone on vasopressin mRNA expression in the bed nucleus of the stria terminalis. J Neurobiol 2003, 54:502-510.

34. Mueller BR, Bale TL: Sex-specific programming of offspring emotionality after stress early in pregnancy. J Neurosci 2008, 28:9055-9065.

35. Planas B, Kolb PE, Raskind MA, Miller MA: Sex difference in coexpression by galanin neurons accounts for sexual dimorphism of vasopressin in the bed nucleus of the stria terminalis. Endocrinology 1995, 136:727-733.

36. de Vries GJ, Jardon M, Reza M, Rosen GJ, Immerman E, Forger NG: Sexual differentiation of vasopressin innervation of the brain: cell death versus phenotypic differentiation. Endocrinology 2008, 149:4632-4637.

37. Amateau SK, McCarthy MM: Induction of PGE2 by estradiol mediates developmental masculinization of sex behavior. Nat Neurosci 2004, 7:643-650.

38. Bale TL: Neuroendocrine and immune influences on the CNS: it's a matter of sex. Neuron 2009, 64:13-16.

39. Petersen SL, Krishnan S, Aggison LK, Intlekofer KA, Moura PJ: Sexual differentiation of the gonadotropin surge release mechanism: A new role for the canonical NfKB signaling pathway. Front Neuroendocrinol 2012, 33:36-44.

40. Pittman QJ, Chen X, Mouihate A, Hirasawa M, Martin S: Arginine vasopressin, fever and temperature regulation. Prog Brain Res 1998, 119:383-392.

41. Donaldson ZR, Young LJ: Oxytocin, vasopressin, and the neurogenetics of sociality. Science 2008, 322:900-904

42. Al-Shamma H, De Vries GJ: Neurogenesis of the sexually dimorphic vasopressin cells of the bed nucleus of the stria terminalis and amygdala of rats. J Neurobiol 1996, 29:91-98.

43. Han TM, De Vries GJ: Neurogenesis of galanin cells in the bed nucleus of the stria terminalis and centromedial amygdala in rats: $A$ model for sexual differentiation of neuronal phenotype. J Neurobiol 1999, 38:491-498.

44. Altman J, Bayer SA: Development of the diencephalon in the rat. i. Autoradiographic study of the time of origin and settling patterns of neurons of the hypothalamus. J Comp Neurol 1978, 182:945-971.

45. Wilkinson MF, Kasting NW: Vasopressin release within the ventral septal area of the rat brain during drug-induced antipyresis. Am J Physiol 1993, 264:R1133-R1138.

46. DeVries GJ, Buijs RM, Van Leeuwen FW, Caffé AR, Swaab DF: The vasopressinergic innervation of the brain in normal and castrated rats. J Comp Neurol 1985, 233:236-254.

47. Wilkinson MF, Horn TF, Kasting NW, Pittman QJ: Central interleukin-1 beta stimulation of vasopressin release into the rat brain: activation of an antipyretic pathway. J. Physiol. (Lond.) 1994, 481(Pt 3):641-646.

48. Spencer SJ, Field E, Pittman QJ: Neonatal programming by neuroimmune challenge: effects on responses and tolerance to septic doses of lipopolysaccharide in adult male and female rats. J Neuroendocrino/ 2010, 22:272-281.

49. Murgatroyd $C$, Patchev AV, Wu Y, Micale $V$, Bockmühl $Y$, Fischer $D$, Holsboer F, Wotjak CT, Almeida OFX, Spengler D: Dynamic DNA methylation programs persistent adverse effects of early-life stress. Nat Neurosci 2009, 12:1559-1566.

50. Baharnoori M, Bhardwaj SK, Srivastava LK: Neonatal Behavioral Changes in Rats With Gestational Exposure to Lipopolysaccharide: A Prenatal Infection Model for Developmental Neuropsychiatric Disorders. Schizophr Bull 2012, 38:444-456.

51. Lee PR, Brady DL, Shapiro RA, Dorsa DM, Koenig Jl: Prenatal stress generates deficits in rat social behavior: Reversal by oxytocin. Brain Res 2007, 1156:152-167.

52. Moore $\mathrm{CL}$ : The role of maternal stimulation in the development of sexual behavior and its neural basis. Ann N Y Acad Sci 1992, 662:160-177.

53. Abel KM, Drake R, Goldstein JM: Sex differences in schizophrenia. Int Rev Psychiatry 2010, 22:417-428.

54. Fombonne E: Epidemiology of pervasive developmental disorders. Pediatr Res 2009, 65:591-598.

55. Ebstein RP, Israel S, Chew SH, Zhong S, Knafo A: Genetics of Human Social Behavior. Neuron 2010, 65:831-844.
56. Green JJ, Hollander E: Autism and oxytocin: new developments in translational approaches to therapeutics. Neurotherapeutics 2010, 7:250-257.

57. Walum H, Westberg L, Henningsson S, Neiderhiser JM, Reiss D, Igl W, Ganiban JM, Spotts EL, Pedersen NL, Eriksson E, Lichtenstein P: Genetic variation in the vasopressin receptor 1a gene (AVPR1A) associates with pair-bonding behavior in humans. Proc Natl Acad Sci USA 2008, 105:14153-14156.

58. Meyer-Lindenberg A, Kolachana B, Gold B, Olsh A, Nicodemus KK, Mattay V, Dean M, Weinberger DR: Genetic variants in AVPR1A linked to autism predict amygdala activation and personality traits in healthy humans. Mol Psychiatry 2009, 14:968-975.

59. Dantzer R: Vasopressin, gonadal steroids and social recognition. Prog Brain Res 1998, 119:409-414.

60. Veenema $A H$, Neumann ID: Central vasopressin and oxytocin release: regulation of complex social behaviours. Prog Brain Res 2008, 170:261-276.

61. de Vries GJ, Södersten P: Sex differences in the brain: the relation between structure and function. Horm Behav 2009, 55:589-596.

doi:10.1186/2042-6410-3-15

Cite this article as: Taylor et al:: Sexually dimorphic effects of a prenatal immune challenge on social play and vasopressin expression in juvenile rats. Biology of Sex Differences 2012 3:15.

\section{Submit your next manuscript to BioMed Central and take full advantage of:}

- Convenient online submission

- Thorough peer review

- No space constraints or color figure charges

- Immediate publication on acceptance

- Inclusion in PubMed, CAS, Scopus and Google Scholar

- Research which is freely available for redistribution 